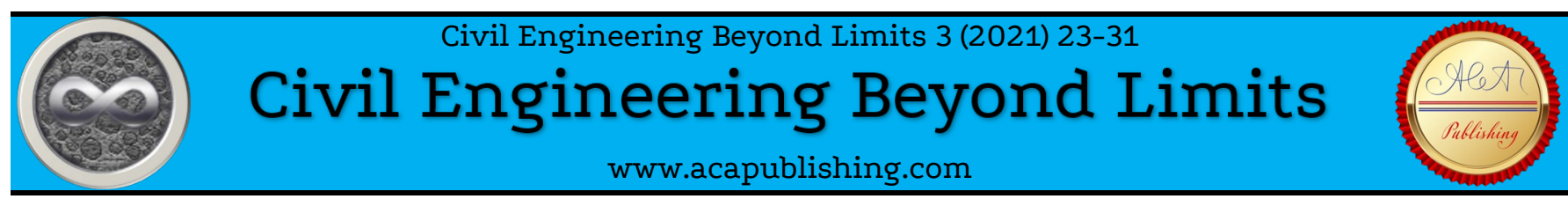

Research Article

\title{
The effect of saturation on the physical and mechanical behavior of some rock samples
}

\author{
Mohammad Taghi Hamzaban *,1, Ismail Sedat Büyüksağiş ${ }^{2}$, Milad Manafi ${ }^{3}$, Ali Touranchehzadeh ${ }^{4}$. \\ ${ }^{1}$ Mining Engineering Faculty, Sahand University of Technology, Tabriz, Iran \\ ${ }^{2}$ Department of Mining Engineering, Afyon Kocatepe University, Afyonkarahisar, Turkey \\ ${ }^{3}$ Mining Engineering Faculty, Sahand University of Technology, Tabriz, Iran \\ ${ }^{4}$ Mining Engineering Faculty, Sahand University of Technology, Tabriz, Iran
}

\section{Keywords}

Intact rock,

Laboratory tests

Saturation,

Mechanical properties,

Porosity.

\begin{abstract}
Different major factors control the strength of solid rocks. Moisture content is one of the most important factors, which can change the physical and mechanical behavior of intact rock as well as rock mass. Several early studies have shown that rock is weaker if tested wet rather than dry. In this paper, the density, P-wave velocity, uniaxial compressive strength, Brazilian tensile strength, and modulus of elasticity of seven different intact rock samples were measured under both dry and saturated conditions. The porosity of the samples was reported as well. Based on the obtained results, some correlations were proposed for estimating the saturated physical and mechanical properties from dry ones. The proposed correlations include different rock types and are more general than the previously reported ones. Comparing the obtained results showed that the mechanical and physical properties of weaker samples are more sensitive to the saturation process. Moreover, among the different mechanical parameters, Brazilian tensile strength exhibited more sensitivity to saturation. Comparing the results with the calculated porosities revealed that porosity is one of the key factors in the effect of saturation on physical and mechanical parameters. It seems that in the more porous rock samples, greater changes in the different measured parameters occur after saturation.
\end{abstract}

\section{Introduction}

The strength of solid rocks is controlled by different factors. The most important ones are 1) Mineralogy, texture and the structure of solid rocks, 2) The structure of rock mass, which determine its strength anisotropy, 3) Water content, and 4) Stress state, which is the result of gravitational stresses and tectonic processes. Under different conditions, the effect of each factor may be quite different and one

Some early studies have revealed that rock materials are weaker when tested under 'wet' conditions rather than 'dry' [2-6]. Colback and Wiid (1965) presented a detailed report on the effect of moisture on the deformability and strength of sedimentary rock formations [1] Burshtein (1969) studied some Russian sedimentary rock samples and revealed the influence of moisture content on the deformability and strength of clay-rich sandstone and quartz arenite. Besides, the results showed that both modulus of deformation and tensile strength are sensitive to the prevailing moisture content for the two studied rock types [7]. Various rock types exhibit different degrees of sensitivity against moisture content. Studying two types of sandstones and three types of limestones, Priest and Selvakumar (1982) proposed a correlation between uniaxial compressive strength (UCS) and moisture content of tested rock types [8]. On the scale of rock mass, the prevailing humidity conditions have a large effect on stability, for example, major slope failures have been reported after heavy rains [9].

Hawkins and McConnell (1992) showed that the sensitivity against moisture content does not necessarily increase in weaker sandstones. Based on the results of multiple regression models, they revealed that the strength loss is largely controlled by the relative proportions of quartz to clay minerals [10]. The nature of the cement material is another controlling factor, which influences the sensitivity against may prove to be major under a given geological condition [1].

moisture. The rocks with ferruginous and calcite types of cement are proved more vulnerable against moisture than those, which contain siliceous cement materials. Hawkins and McConnell (1992) revealed that the lower sensitivity classes of sandstones generally have relatively high contents of quartz minerals. Moreover, the higher the proportions of rock fragments and clay minerals, the greater the sensitivity against water content. Based on their findings, in clay-rich sandstones, the clay softening process is an important factor in the creation of moisture sensitivity [10].

To explain the weakening process of saturated rock materials, several mechanisms are often used, such as 1) the reduction of fracture energy, 2) the decrease of capillary tension, 3) the increase of pore pressure, 4) frictional reduction, and 5) chemical deterioration as well as corrosion. For certain loading conditions and rock types, some of these mechanisms are more likely than others. As the rock is compressed, its pore fluids are pressurized and an outward pressure gradient is created. This leads to reducing the strength. One other general category, which must be considered also, is mineralogical changes due to water absorption. In the presence of expandable clay minerals, this effect is more severe [6]. Wong et al. (2016) have discussed that in addition to the water content, there are other internal and external factors, which cause a reduction in rock deformability and strength. Some internal factors are density, porosity, and fabric. Among the external factors, strain rate, the dielectric constant of the saturation liquid, and surface tension are the key ones. Suction process and absorption percentage also have a significant effect [11].

Dyke and Dobereiner (1991) showed the correlation between uniaxial compressive strength (UCS) and water content for three quartz arenites [12]. During the investigations on the stability of coal underground mines, Colback and Wiid (1965) developed a linear correlation for the uniaxial compressive strength (UCS) of immersed sandstones [2]. It has been shown that the major part of the strength 
reduction occurs when the moisture content is approximately equal to one-third of the water content at saturation [10]. A linear correlation between uniaxial compressive strengths under dry and saturated conditions has also been reported for limestone and sandstone samples [13 and 14]. The studies revealed that the slope of the fitted trend line is nearly the same for uniaxial compressive strength and tensile strength values in dry and saturated conditions [13]. Shi et al. (2016) have sown that there is a clear negative exponential relationship between the UCS values of 14 different sandstones and water contents [15]. Majeed and Abu Bakar (2018) stated that overall UCS and BTS (Brazilian tensile strength) values of sedimentary rocks in the saturated condition are approximately 0.57 and 0.50 times that of UCS and BTS values in the dry state respectively [16].

It has been shown that Young's modulus also decreases in wet conditions [4, 17, and 18]. The results indicated one clear trend: a decrease in modulus of elasticity $(E)$ and an increase in Poisson's ratio (V) with increasing moisture contents [10]. Vásárhelyi (2005) has reported a linear correlation between the Esat and Edry for limestones [13]. Hawkins and McConnell (1992) revealed that the shape of $\sigma-\varepsilon$ (stress-strain) curves does not change significantly in the sandstones, which exhibit a high degree of elasticity in the dry state. However, in many cases, the consequence of saturation is a more 'S-shaped' stressstrain curve. This means that the saturation results in less elastic deformation. The relationship between $E_{s e c}$ (second modulus of elasticity) and moisture content is stronger than that of $E_{\tan }$ (tangent modulus of elasticity). The main reason, as mentioned, is the development of a more S-shaped $\sigma-\varepsilon$ curve in the presence of pore water [10].

In addition to the water content changes, Zhou et al. (2016) studied the effect of water distribution inside testing samples during saturating and drying processes. They showed that on a sandstone specimen the compressive strength does not exhibit any obvious difference during the saturation and drying processes. However, there is a significant distinction for the tensile strength values of samples with the same water content but in different processes, i.e. different water distributions inside the testing samples [19]. In another attempt to study the effect of water distribution on UCS values, Li and Wang (2019) proposed two parameters of critical saturation degree $\left(S_{r c}\right)$ and the variation of saturation degree per unit length $(k)$. Using these two parameters, they calculated $U C S$ values with varying $S_{r C}[20]$.

Some other authors have found that when exposed to high relative humidity, rock samples' fracture toughness decreases. They founded that the decrease is more significant if the rock samples contain expansive clay minerals such as smectite [21 and 22].

Testing on artificially created discontinuities on marl samples, Pellet et al. (2013) revealed that the behavior of discontinuities differs significantly under dry and saturated conditions. The lubricant effect of water lowers the friction angle considerably for the saturated discontinuities. At the same time, cohesion slightly decreases. Moreover, in the existence of moisture, normal and shear stiffness values change significantly [9]. Li et al. (2020) performed direct shear tests on sandstone and granite fractures under the different conditions of dry, surface wet, and saturated conditions. Based on the obtained results, they discussed the effect of moisture conditions on the shear strength of discontinuities. The results revealed a monotonic decreasing trend for the peak and residual shear strength from dry to surface wet and finally saturated conditions [23].

The reviewed studies show the importance of the prevailing moisture content on the performance of rock material in rock engineering projects such as subsurface excavations or road cuttings. This highlights the effect of testing conditions, i.e. dry, saturated, or intermediate moisture content, on the measured parameters. For major engineering projects, it is strongly recommended that the UCS under dry conditions be obtained for strength classifications. In contrast, during the actual engineering designs, it is highly recommended to consider the potential change in the deformability and strength of rock material due to the moisture sensitivity [10].

In this paper, the effect of saturation on the mechanical and physical properties of seven different rock types has been investigated. Moreover, based on the obtained results, it has been shown that how the saturation effect differs in various rock samples.

\section{Testing process}

Testing samples include seven different intact rock types: two kinds of andesite with different mechanical properties (of a quarry mine in Nire), basalt (of a quarry mine in Ardebil), granite (of a quarry mine in Ahar), onyx (of a quarry mine in Azarshahr), sandstone (of Varzeghan district), and travertine (of a quarry mine in Azarshahr). The all mentioned mines are located in the North West of Iran. Considering ISRM recommendations for rock sample preparation [24], core samples were prepared from each rock type (Fig. 1). To do this, several blocks of different rock types, from the mentioned quarries, were transferred to the laboratory. Rock cores in the diameter of $54 \mathrm{~mm}$ (NX size) were cut using an electrical core drilling machine from the blocks. A laboratory core sawing machine was used to cut the end parts of the prepared cores considering the recommended length to diameter ratio of 2.5 [24].

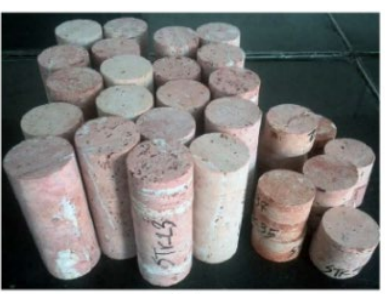

(a)

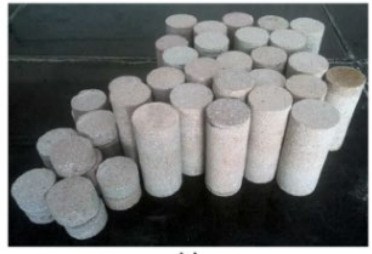

(c)

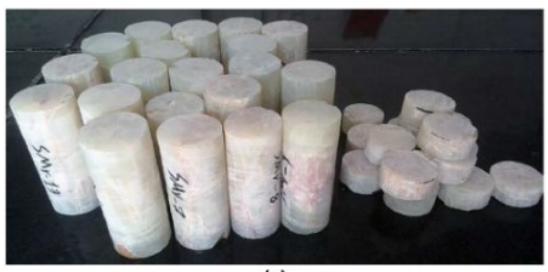

(e)

Figure 1. Photos of some prepared rock samples: a) travertine, b) basalt, c) andesite, d) sandstone, and e) onyx

The testing program includes the measurement of density $(\rho)$, P-wave velocity $\left(V_{P}\right)$, uniaxial compressive strength (UCS), modulus of elasticity (E), and Brazilian tensile strength (BTS) for both dry and saturated samples. The saturation process was performed based on the ISRM recommendations [24]. In the first step, the non-destructive tests for measuring $\rho$ and $V_{P}$ values were performed on all core samples. Density was calculated as the ratio of the sample mass, measured with a balance, to the sample volume. Moreover, an ultrasonic testing device was used to measure $V_{P}$ values (Fig. 2). Weight volume relationships were used to calculate the porosity $(n)$ of rock samples from $\rho$ dry and $\rho_{\text {sat }}$ values. In addition to nondestructive tests, the testing program included five uniaxial compressive tests and five Brazilian tensile tests for each group of rock samples separately in dry and saturated conditions. Consequently, the overall count of UCS and BTS tests in the testing program was 70. An automatic hydraulic compression press was used to perform UCS and BTS tests (Fig. 3-a). Modulus of elasticity was measured simultaneously with the UCS tests. To do this, a load cell and a displacement sensor were used along with a data logger (Fig. 3b) to plot stress-strain curves. Fig. 4 shows a set of stress-strain curves plotted for dry andesite samples. Finally, an ISRM recommended 
testing frame was used to measure BTS values (Fig. 3-c). All tests were performed based on the ISRM standard recommendations [24].

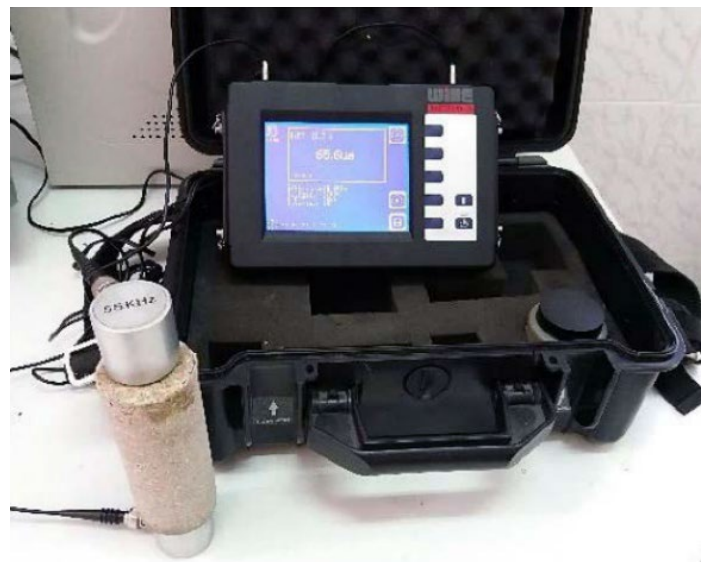

Figure 2. The ultrasonic testing device used to measure $V_{P}$ values

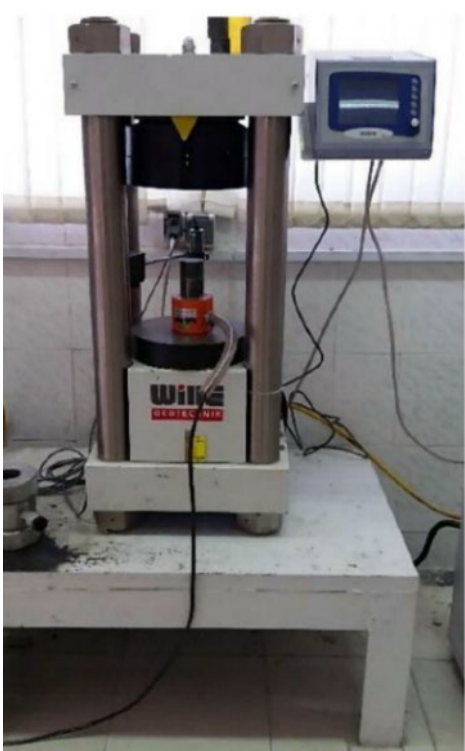

(a)

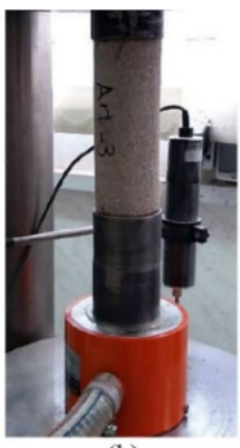

(b)

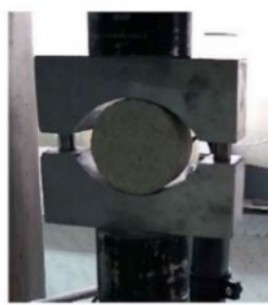

(c)
Figure 3. a) Compressive testing machine used to perform UCS and $B T S$ tests, b) Measuring sample load and displacement in a uniaxial compression test, c) BTS loading frame.

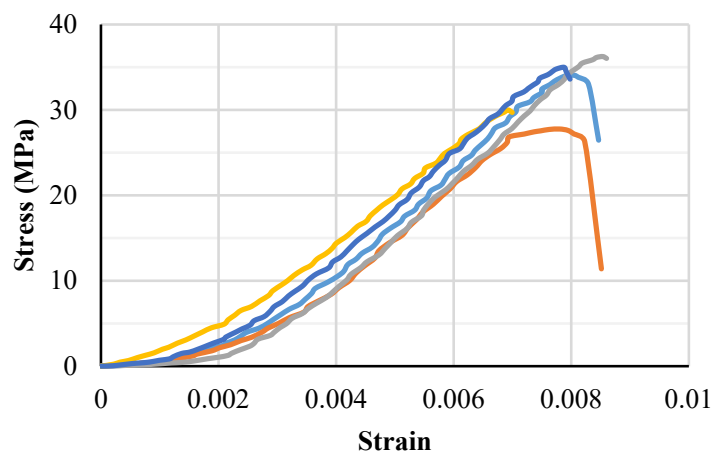

Figure 4. Stress - strain curves plotted for sandstone samples

\section{Results and Discussion}

Table 1 summarizes the results of the testing program. The calculated average values along with the relevant standard deviation of different tests performed on each rock type are included in the table.
Fig. 5 shows the correlation between the different physical and mechanical parameters of tested samples in the dry and saturated conditions. To have a better sense of the obtained trends, the 1:1 line is showed on the plots as well. The obtained correlation coefficients are considerable and there are strong correlations between the measured parameters under dry and saturated conditions. Therefore, it seems that one can estimate the saturated values from the dry ones with an acceptable accuracy level. The following equations express the obtained correlations:

$\begin{array}{ll}\rho_{\text {sat }}=0.8081 \rho_{d r y}+534.51 & R^{2}=0.8895 \\ V_{P \text {-sat }}=1.0249 V_{P-d r y}+120.08 & R^{2}=0.9690 \\ U C S_{\text {sat }}=1.0079 U C S_{d r y}-8.9858 R^{2}=0.9690 \\ B T S_{\text {sat }}=1.0813 B T S_{d r y}-2.2171 & R^{2}=0.7603 \\ E_{\text {sat }}=0.7377 E_{d r y}-1.7473 & R^{2}=0.8440\end{array}$

Where $\rho$ is the density, $V_{P}$ is the P-wave velocity, UCS is the uniaxial compressive strength, BTS is the Brazilian tensile strength, and $E$ is the modulus of elasticity. Subscribes dry and sat refer to the dry and saturated conditions respectively. The most important characteristic of equations 1 to 5, compared to the previously developed ones in the literature, is that they include various rock types rather than a particular rock material. This means that the generalization of the proposed correlations is greater than the previous ones. However, it is clear that performing more tests and including other rock types will increase the generalization of the obtained correlations.

In the plots of Figs 5-a and 5-b, all data points and relevant trends are placed above the 1:1 line. This means that in all conditions, the saturated values of density and P-wave velocity are greater than the dry ones. This is quite reasonable due to the effect of water in the filling of pore spaces under saturated conditions. However, in the plots of Figs 5-c, 5-d, and 5-e, the data points and fitted trend lines are placed under the 1:1 line. This means that the saturated values of uniaxial compressive strength, Brazilian tensile strength, and modulus of elasticity are smaller than the dry ones. This is in line with the findings of the previously reviewed works. Another important point in Fig. 5-a is that the fitted trend line closes to the 1:1 line with the increase of the density values. In other words, the higher the density, the closer the dry and saturated values, and the smaller the effect of saturation. Such a trend does not be seen in the plots of Figs 5-b, 5-c, and 5-d. Graph 5-e exhibits an opposing trend and it seems that the difference between $E_{d r y}$ and $E_{s a t}$ values increases with the increase of $E_{d r y}$ amounts. The reason for these trends will be discussed in the next plots. To have a better vision of the obtained results in the saturated conditions, the ratio of saturated to the dry values is plotted against the dry values in Fig. 6. In Figs 6-a and 6-b, data points and relevant trends are placed above the range of $100 \%$. This shows that the values of density and P-wave velocity in the saturated state are greater than those of dry ones. However, it can be seen that in the plot of Fig. 6-a the ratio of $\rho_{\text {sat }} / \rho_{d r y}$ approximates the unity in the high $\rho_{\text {dry }}$ values. Hence, as was noted before, the difference between $\rho_{\text {sat }}$ and $\rho_{d r y}$ decreased in the denser samples. The ratio of $V_{P-s a t} / V_{P-d r y}$ does not exhibit any trend with the values of $V_{P-d r y}$ and it seems that overall $V_{P}$ range the increase of $V_{P \text {-sat }}$ values is more or less the same. The graphs of Figs 6-c, 6-d, and 6-e reveals similar trends. The ratio of saturated to dry values increases in stronger rock samples. From another viewpoint, the weaker the rock sample, the smaller the ratio of saturated to dry values. This means that weaker rock samples experience a greater decrease in the mechanical parameters when they are saturated. Comparing the plots of Figs $6-c, 6-d$, and 6-e reveals that the range of saturated to dry ratios in y-axes is greater for the results of BTS (Fig. 6-d). In other words, it seems that the sensitivity of Brazilian tensile strength values to saturation is greater than the other mechanical parameters of uniaxial compressive strength and elastic modulus. 
Table 1. Summary of the results obtained from testing program

\begin{tabular}{|c|c|c|c|c|c|c|c|c|}
\hline & & Andesite-1 & Andesite-2 & Basalt & Granite & Onyx & Sandstone & Travertine \\
\hline \multirow{2}{*}{$\begin{array}{c}\rho_{d r y} \\
\left(\mathrm{~kg} / \mathrm{m}^{3}\right)\end{array}$} & Ave. & 1960 & 2536 & 2105 & 2600 & 2659 & 2310 & 2383 \\
\hline & StD. & 2 & 12 & 37 & 4 & 38 & 10 & 40 \\
\hline \multirow{2}{*}{$\begin{array}{c}\rho_{\text {sat }} \\
\left(\mathrm{kg} / \mathrm{m}^{3}\right)\end{array}$} & Ave. & 1999 & 2583 & 2357 & 2605 & 2661 & 2454 & 2458 \\
\hline & StD. & 43 & 12 & 135 & 3 & 38 & 12 & 31 \\
\hline \multirow{2}{*}{$\begin{array}{c}n \\
(\%)\end{array}$} & Ave. & 9.84 & 2.15 & 7.15 & 0.52 & 5.00 & 9.18 & 5.71 \\
\hline & StD. & 1.76 & 0.13 & 2.14 & 0.09 & 1.02 & 1.18 & 1.43 \\
\hline \multirow{2}{*}{$\begin{array}{l}V_{P-d r y} \\
(\mathrm{~m} / \mathrm{s})\end{array}$} & Ave. & 3171 & 4699 & 4697 & 5514 & 5404 & 2658 & 4606 \\
\hline & StD. & 335 & 99 & 53 & 74 & 140 & 329 & 172 \\
\hline $\begin{array}{l}V_{P-s a t} \\
(\mathrm{~m} / \mathrm{s})\end{array}$ & StD. & 612 & 90 & 285 & 90 & 67 & 477 & 135 \\
\hline \multirow{2}{*}{$\begin{array}{l}U C S_{d r y} \\
\text { (MPa) }\end{array}$} & Ave. & 46.3 & 80.0 & 63.6 & 75.9 & 47.0 & 35.4 & 43.5 \\
\hline & StD. & 0.9 & 16.2 & 8.6 & 3.7 & 11.0 & 4.3 & 3.2 \\
\hline \multirow{2}{*}{$\begin{array}{l}U C S_{\text {sat }} \\
(\mathrm{MPa})\end{array}$} & Ave. & 33.8 & 71.0 & 51.7 & 70.1 & 40.4 & 25.5 & 39.2 \\
\hline & StD. & 5.3 & 6.7 & 21.7 & 5.1 & 5.3 & 2.7 & 5.5 \\
\hline \multirow{2}{*}{$\begin{array}{c}E_{d r y} \\
(\mathrm{GPa})\end{array}$} & Ave. & 11.3 & 21.0 & 17.4 & 20.0 & 19.5 & 8.0 & 16.2 \\
\hline & StD. & 1.6 & 2.3 & 3.1 & 1.3 & 5.1 & 1.8 & 3.0 \\
\hline $\begin{array}{c}E_{s a t} \\
(\mathrm{GPa})\end{array}$ & Ave. & 7.8 & 11.5 & 10.1 & 13.9 & 14.8 & 3.2 & 10.0 \\
\hline \multirow{2}{*}{$\begin{array}{l}B T S_{d r y} \\
(\mathrm{MPa})\end{array}$} & Ave. & 5.4 & 7.5 & 7.1 & 6.2 & 6.6 & 3.8 & 6.8 \\
\hline & StD. & 0.2 & 0.6 & 0.6 & 0.3 & 0.8 & 0.3 & 0.6 \\
\hline \multirow{2}{*}{$\begin{array}{l}B T S_{\text {sat }} \\
\text { (MPa) }\end{array}$} & Ave. & 2.8 & 4.9 & 6.1 & 5.2 & 4.4 & 2.0 & 5.9 \\
\hline & StD. & 0.1 & 0.6 & 0.5 & 1.1 & 0.7 & 0.7 & 0.3 \\
\hline
\end{tabular}

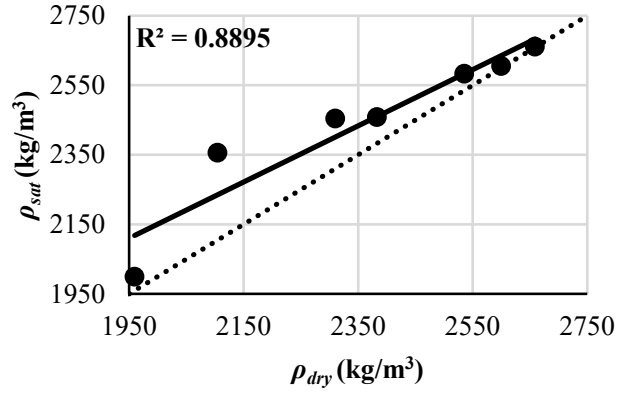

(a)

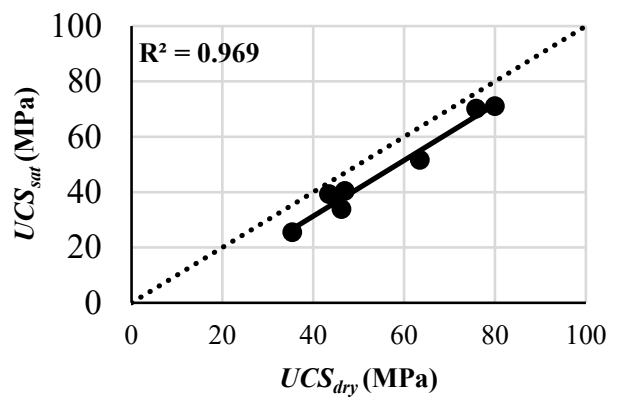

(c)

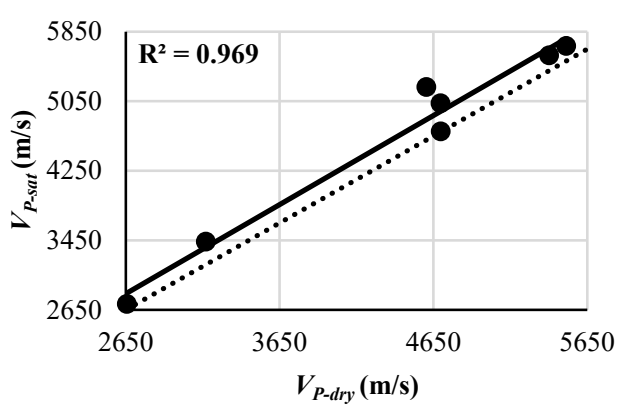

(b)

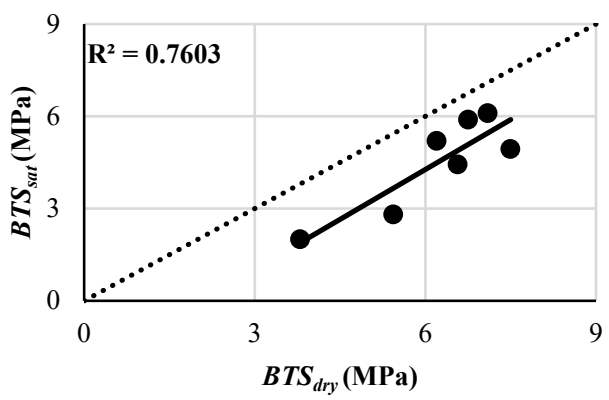

(d)

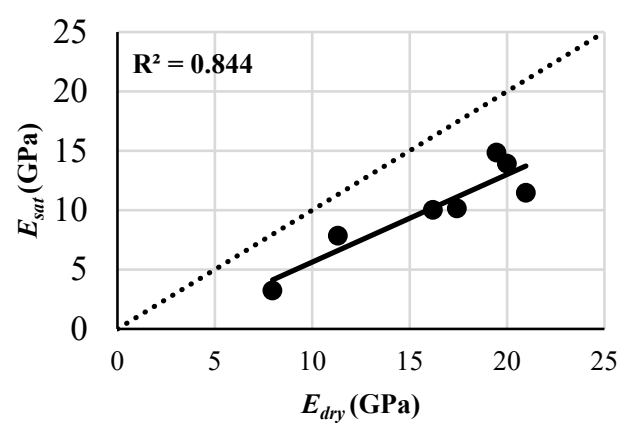

(e)

Figure 5. correlations between the dry and saturated values of a) density $(\rho)$, b) P-wave velocity ( $\left.V_{P}\right)$, c) uniaxial compressive strength (UCS), d) Brazilian tensile strength (BTS), and e) modulus of elasticity ( $E$ ) 


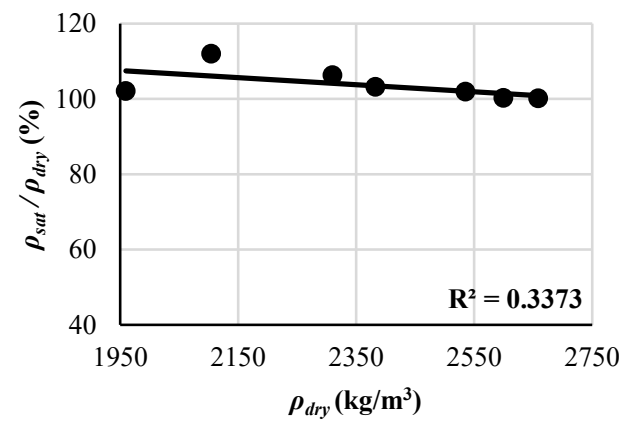

(a)

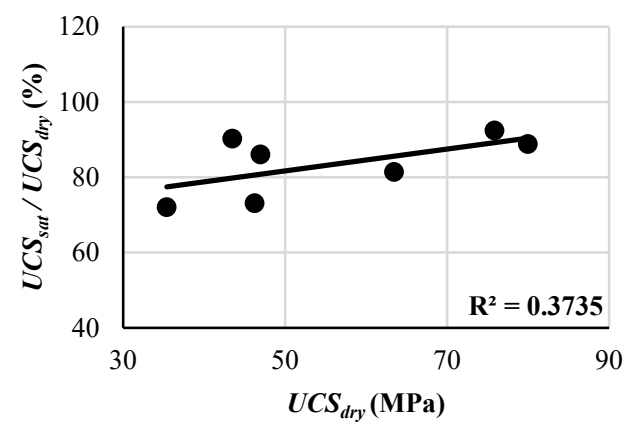

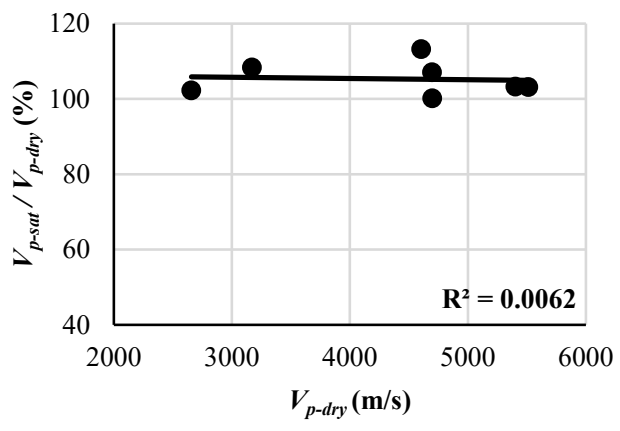

(b)

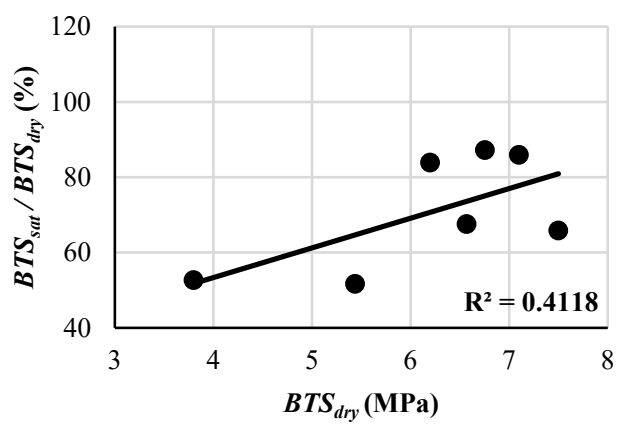

(d)

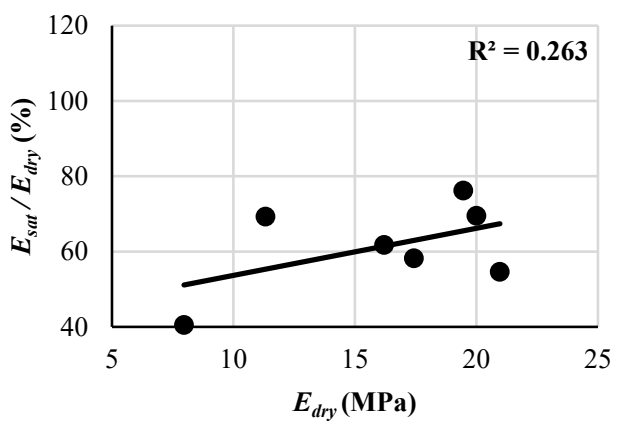

(e)

Figure 6. The variations of saturated to dry ratios for a) density $(\rho)$, b) P-wave velocity $\left(V_{P}\right)$, c) uniaxial compressive strength (UCS), d) Brazilian tensile strength (BTS), and e) modulus of elasticity $(E)$

To have a better insight into the obtained trends under dry and saturated conditions, the measured porosity values were used. It seems that increasing the porosity of rock samples provides more vacant spaces inside the tested samples, which are filled with water during the saturation process. Therefore, it can be expected that the more the porosity of rock samples, the greater the difference between the dry and saturated parameters. Fig. 7 shows the correlations between the different parameters and porosities under dry and saturated conditions. The fitted linear trend lines are plotted as well. The fitted lines on saturated data points are above the dry ones in Figs $7-\mathrm{a}$ and 7-b. These trends again show that the values of $\rho$ sat and $V_{P \text {-sat }}$ are greater than those of $\rho_{d r y}$ and $V_{P-d r y}$ respectively. In Fig. 7-a, the distance between the fitted trend lines increases with the increase of porosity values. In other words, the difference between $\rho$ sat and $\rho$ dry increases with the increase of porosities. The same condition prevails in Figs 7-c and 7-d. However, the fitted trends under dry conditions are above saturated ones (i.e. dry values are greater than saturated values) in these plots. The fitted trend lines in Fig. 7-e close together with the increase of porosity. It seems that this contradictory result for $E$ values is due to the low count of data points and measuring errors. The trend lines of Fig. 7-b are parallel. This means that changing the values of porosity does not change the difference

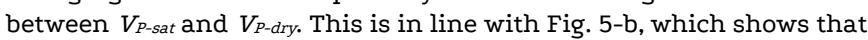
the distance of the fitted trend line with the 1:1 line is more or less the same. These results confirm the first assumption that in the more porous samples, the difference between saturated and dry values increases.

Fig. 8 shows the graphs of the ratio of saturated to dry values against porosities for different physical and mechanical parameters. Except for the UCS graph (Fig. 8-C), the correlation coefficients are not so high but the obtained trends are quite reasonable. The trend lines in Figs 8-a and 8-b are ascending. In other words, in more porous samples, the increase of $\rho$ sat and $V_{P \text {-sat }}$ are greater. The low-slope ascending trend of Fig. 8-b denies the results of Figs 7-b and 5-b, which have been discussed before. However, the greater difference of saturated $V_{P}$ values comparing to the dry ones in more porous samples (i.e. the trend line of Fig. 8-b) is more reasonable. The obtained trends in Figs 8-c to 8-d are descending. In other words, with the increase of the porosity of tested samples, a higher degree of weakness appears in the mechanical properties of saturated samples comparing to the dry ones. 
If the porosity is accepted as one of the main factors on the degree of weakness, which appears in the saturated state, when $n=0$, the ratio of saturated to dry values should become $100 \%$. In other words, the fitted trend lines in the plots of Fig. 8 should intercept the vertical axes at $100 \%$ point, or at least introducing the $n=0$ and $100 \%$ point to the graphs should improve the degree of correlations. The mentioned point is added to the graphs of different parameters in Fig.
9. Comparing the plots of Figs 8 and 9 reveals that the added point has increased the correlation coefficient in all graphs. Therefore, the porosity of rock samples is one of the key factors in the change of physical and mechanical parameters during the saturation process.

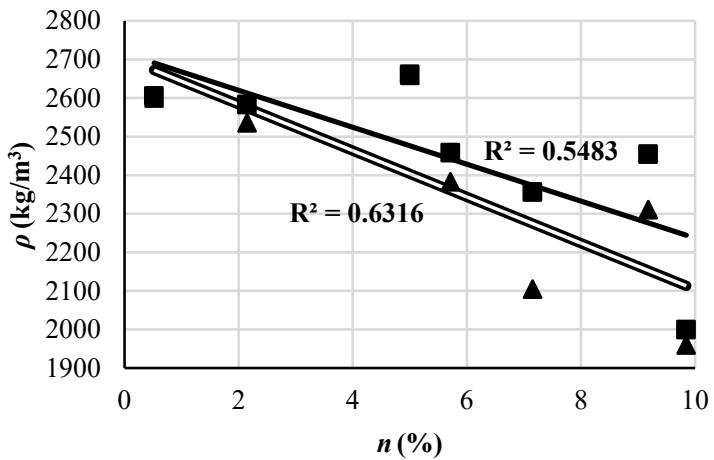

$\Delta$ Dry $\mathbf{\square}$ Saturated

(a)

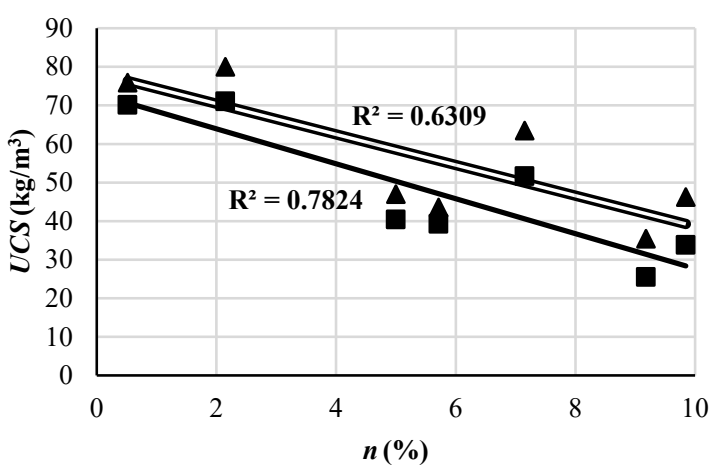

$\Delta$ Dry $\mathbf{D}$ Saturated

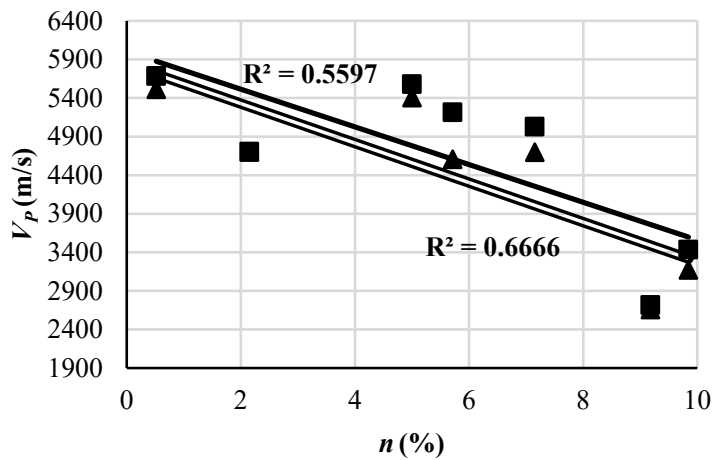

$\Delta$ Dry $\mathbf{D}$ Saturated

(b)

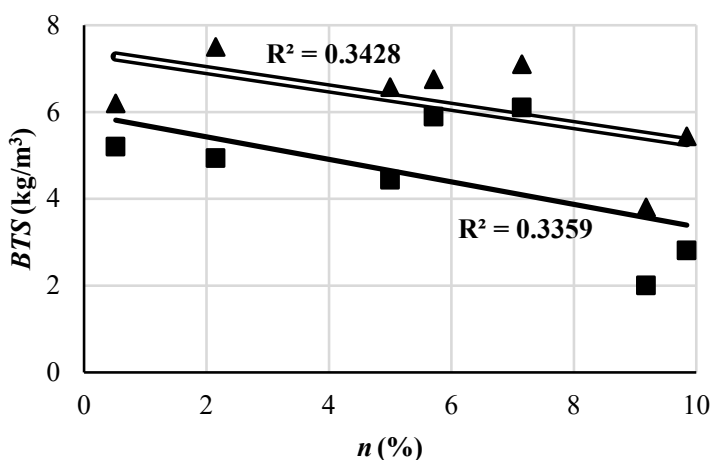

$\Delta$ Dry $\mathbf{\square}$ Saturated

(d)

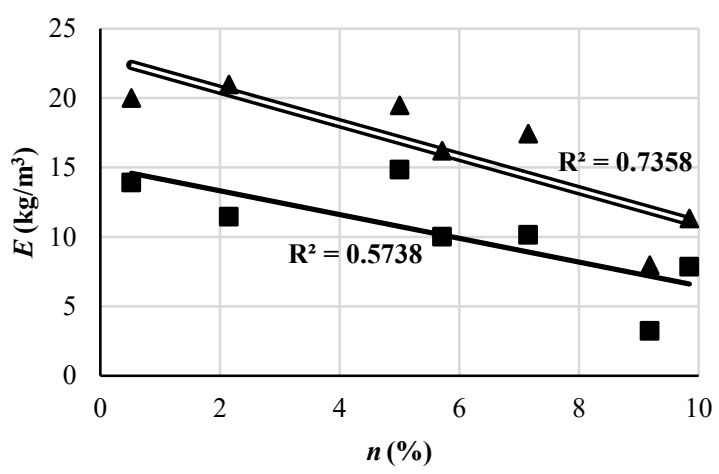

$\Delta$ Dry $\boldsymbol{\square}$ Saturated

(e)

Figure 7. The variations of the saturated and dry values of different parameters against porosity a) density $(\rho)$, b) P-wave velocity ( $\left.V_{P}\right)$, c) uniaxial compressive strength (UCS), d) Brazilian tensile strength (BTS), and e) modulus of elasticity (E) 


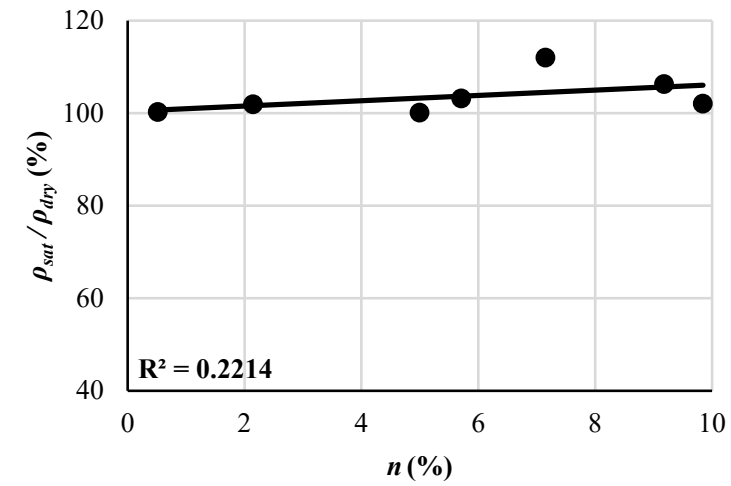

(a)

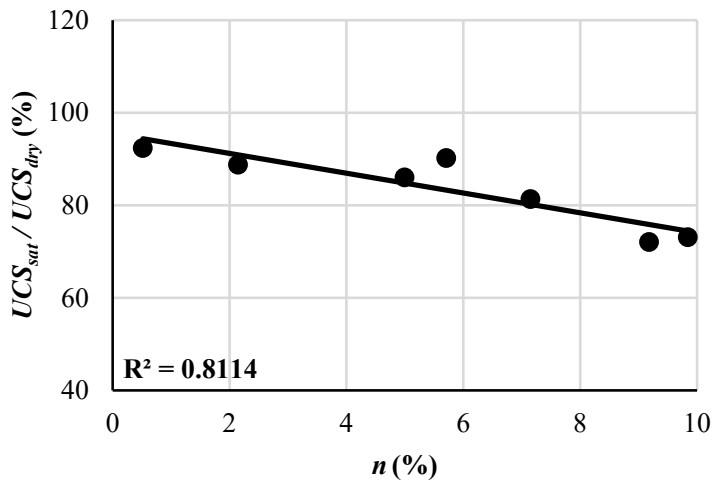

(c)

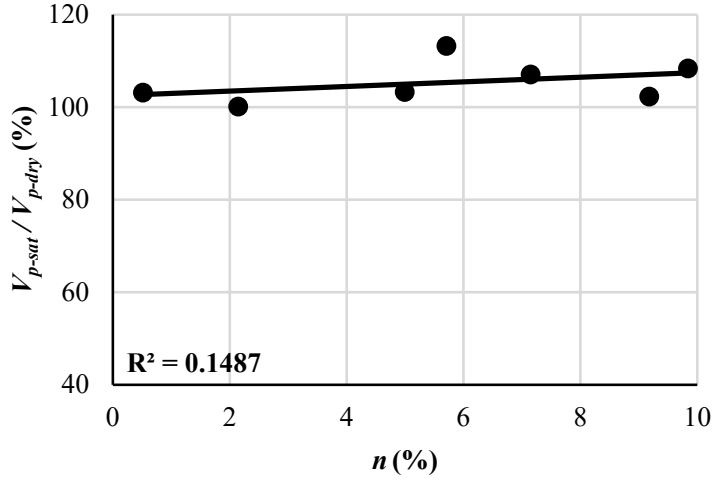

(b)

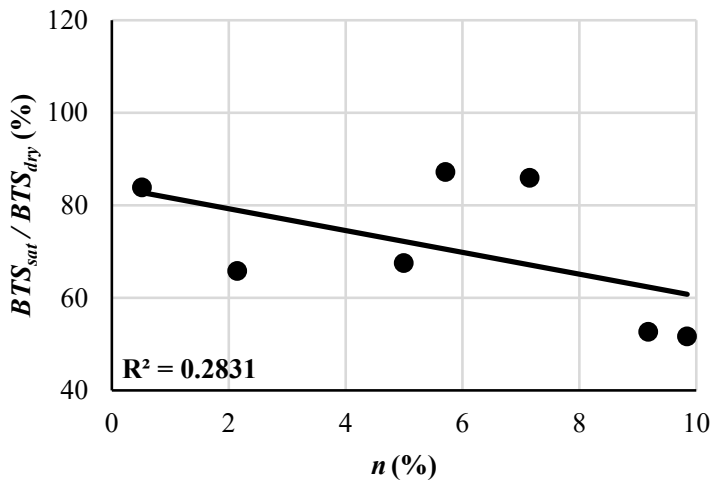

(d)

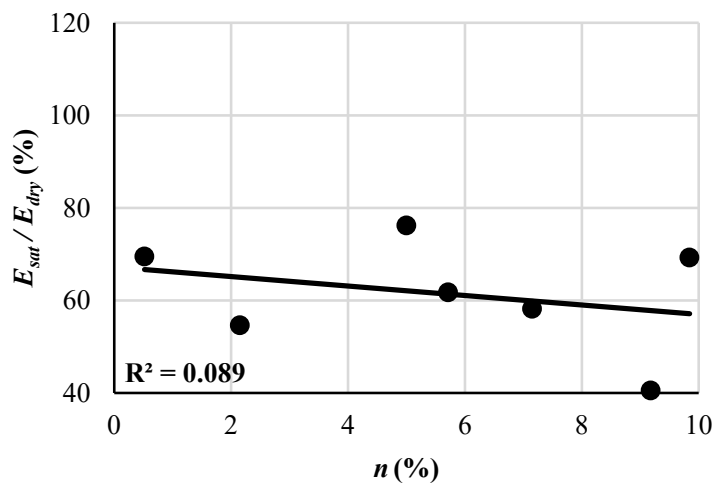

(e)

Figure 8. The variations of saturated to dry ratios against porosities for a) density $(\rho)$, b) P-wave velocity ( $V_{P}$ ), c) uniaxial compressive strength (UCS), d) Brazilian tensile strength (BTS), and e) modulus of elasticity ( $E$ ) 


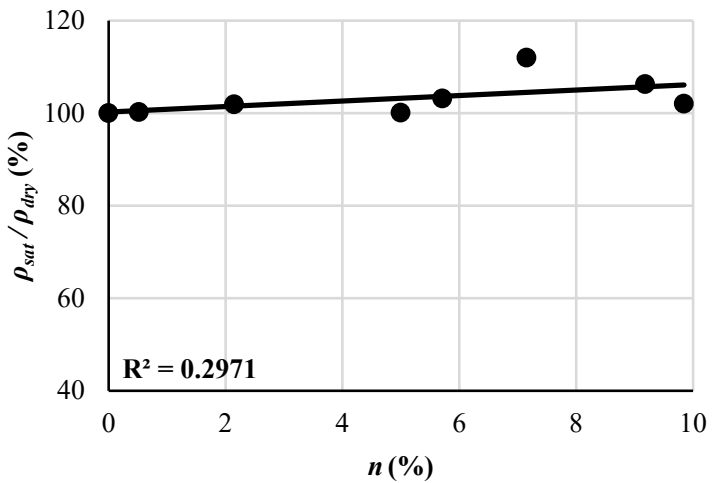

(a)

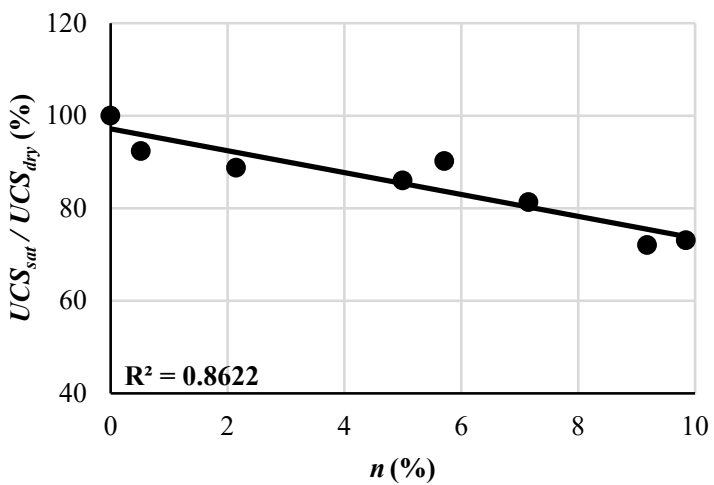

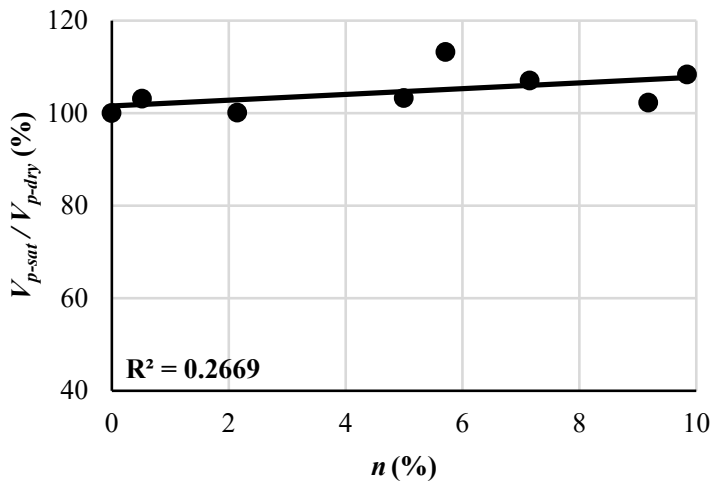

(b)

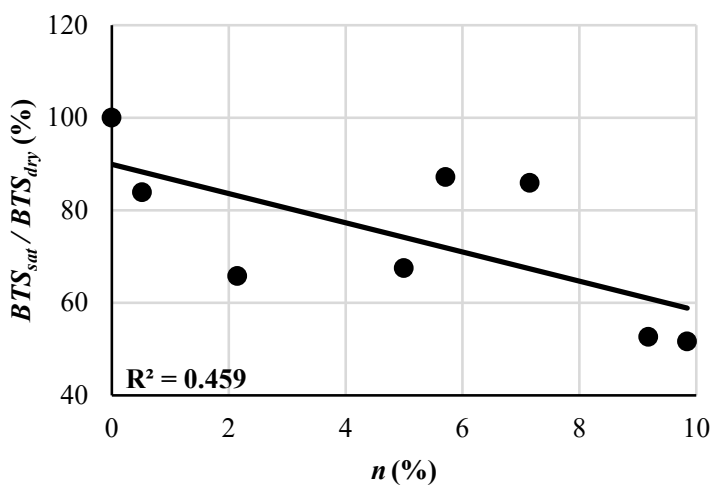

(d)

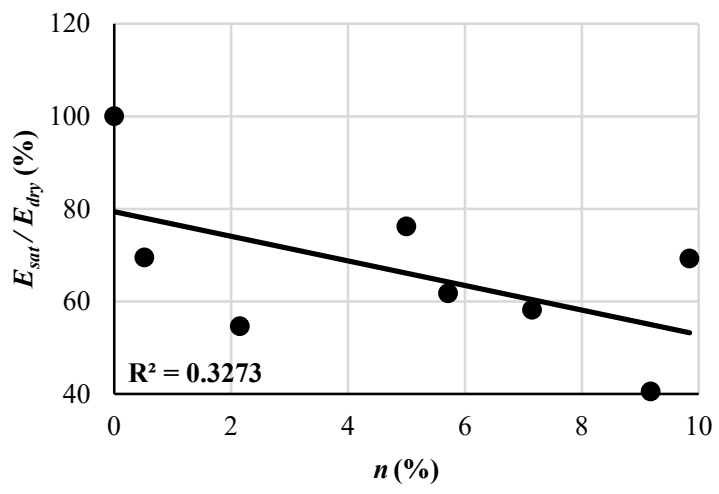

(e)

Figure 9. The variations of saturated to dry ratios against porosities (including $n=0$ and $100 \%$ point) for a) density $(\rho)$, b) P-wave velocity ( $V_{P}$ ), c) uniaxial compressive strength (UCS), d) Brazilian tensile strength (BTS), and e) modulus of elasticity (E)

\section{Conclusion}

In this paper, some physical and mechanical parameters of seven rock samples were measured in dry and saturated conditions. Based on the obtained results:

- The saturated values of different physical and mechanical parameters can be estimated from the dry ones with acceptable accuracy. The proposed correlations include the results of different rock types and are more generalized than the previously reported correlations.In the weaker samples, a greater decrease in the mechanical parameters occurs after saturation.
- The sensitivity of Brazilian tensile strength to saturation is greater than other mechanical parameters. The main reason for this is that when the water filling the pores of the rocks is compressed, it causes pushing forces to the sides, in other words, it causes the tensile force of the rock outward. This causes saturated rocks to have lower tensile strength than dry ones.

- The porosity of rock samples is one of the key factors in the effect of saturation on their physical and mechanical properties.

- The greater the porosity of the rock sample, the greater the difference between saturated and dry parameters. 


\section{Nomenclature}

$B T S$ : Brazilian tensile strength

$B T S_{\text {dry }}$ : Brazilian tensile strength at dry condition

$B T S_{\text {sat }}$ : Brazilian tensile strength at saturated condition

$E$ : modulus of elasticity

$E_{d r y}$ : modulus of elasticity at dry condition

$E_{\text {sat }}:$ modulus of elasticity at saturated condition

$E_{s e c}$ : secant modulus of elasticity

$E_{\text {tan }}$ : tangential modulus of elasticity

$k$ : saturation degree per unit length

$n$ : porosity

$S_{r c}$ : critical saturation degree

UCS : uniaxial compressive strength

$U C S_{d r y}$ : uniaxial compressive strength at dry condition

$U C S_{\text {sat }}$ : uniaxial compressive strength at saturated condition

$V_{P}:$ P-wave velocity

$V_{P-d r y}:$ P-wave velocity at dry condition

$V_{P \text {-sat }}:$ P-wave velocity at saturated condition

$\rho$ : density

$\rho_{\text {dry }}:$ dry density

$\rho_{\text {sat }}$ : saturated density

$v$ : Poison's ratio

\section{Declaration of Conflict of Interest}

The authors declare that there is no conflict of interest. They have no known competing financial interests or personal relationships that could have appeared to influence the work reported in this paper.

\section{References}

[1.] Golodkovskaia, G., Krasilova, N., Ladygin, V., Shaumian, L. Factors controlling solid rock strength. Bulletin of the International Association of Engineering Geology 11(1975)65-69.

[2.] Colback, P., Wiid, B. The influence of moisture content on the compressive strength of rocks. Geophysics (1965).

[3.] Parker, J. Temperature and humidity affect strength of rock structures at White Pine. Transactions of the Society of Mining AIME 247(1970)142-144.

[4.] Wiid, B. The influence of moisture on the pre-rupture fracturing of two rock types. In: Proc, 1st International Society of Rock Mechanics (1970)1-19.

[5.] Parate, N. Influence of water on the strength of limestone. Transactions of the Society of Mining AIME 254(1973)127-131.

[6.] Van Eeckhout, E.M. The mechanisms of strength reduction due to moisture in coal mine shales. International Journal of Rock Mechanics and Mining Sciences \& Geomechanics Abstracts 13(1976)61-67.

[7.] Burshtein, L. Effect of moisture on the strength and deformability of sandstone. Soviet Mining 5(1969)573-576.

[8.] Priest, S., Selvakumar, S. The failure characteristics of selected British rocks. Monograph (1982).

[9.] Pellet, F., Keshavarz, M., Boulon, M. Influence of humidity conditions on shear strength of clay rock discontinuities. Engineering Geology 157(2013)33-38.

[10.] Hawkins, A., McConnell, B. Sensitivity of sandstone strength and deformability to changes in moisture content. Quarterly Journal of Engineering Geology and Hydrogeology 25(1992)115-130.
[11.] Wong, L.N.Y., Maruvanchery, V., Liu, G. Water effects on rock strength and stiffness degradation. Acta Geotechnica 11(2016)713-737

[12.] Dyke, C., Dobereiner, L. Evaluating the strength and deformability of sandstones. Geological Society of London (1991)123-134.

[13.] Vásárhelyi, B. Statistical analysis of the influence of water content on the strength of the Miocene limestone. Rock Mechanics and Rock Engineering 38(2005)69-76.

[14.] Vásárhelyi, B., Ván, P. Influence of water content on the strength of rock. Engineering Geology 84(2006)70-74.

[15.] Shi, X., Cai, W., Meng, Y., Li, G., Wen, K., Zhang, Y. Weakening laws of rock uniaxial compressive strength with consideration of water content and rock porosity. Arabian Journal of Geosciences 9(2016)369.

[16.] Majeed, Y., Bakar, M.A. Water saturation influences on engineering properties of selected sedimentary rocks of Pakistan. Journal of Mining Science 54(2018)914-930.

[17.] Van Eeckhout, E.M., Peng, S.S. The effect of humidity on the compliances of coal mine shales. International Journal of Rock Mechanics and Mining Sciences \& Geomechanics Abstracts 12(1975)335-340.

[18.] Gutierrez, M., Øino, L., Høeg, K. The effect of fluid content on the mechanical behavior of fractures in chalk. Rock Mechanics and Rock Engineering 33(2000)93-117.

[19.] Zhou, Z., Cai, X., Cao, W., Li, X., Xiong, C. Influence of water content on mechanical properties of rock in both saturation and drying processes. Rock Mechanics and Rock Engineering 49(2016)30093025.

[20.] Li, D., Wang, W. Quantitative analysis of the influence of saturation on rock strength reduction considering the distribution of water. Geomechanics and Geophysics for GeoEnergy and Geo-Resources 5(2019)197-207.

[21.] Nara, Y., Morimoto, K., Hiroyoshi, N., Yoneda, T., Kaneko, K. Benson, P.M. Influence of relative humidity on fracture toughness of rock: implications for subcritical crack growth. International Journal of Solids and Structures 49(2012)24712481.

[22.] Maruvanchery, V., Kim, E. Effects of water on rock fracture properties: Studies of mode I fracture toughness, crack propagation velocity, and consumed energy in calcite-cemented sandstone. Geomechanics and Engineering 17(2019)57-67.

[23.] Li, B., Ye, X., Dou, Z., Zhao, Z., Li, Y., Yang, Q. Shear strength of rock fractures under dry, surface wet and saturated conditions. Rock Mechanics and Rock Engineering 53(2020)2605-2622.

[24.] Ulusay, R. The ISRM suggested methods for rock characterization, testing and monitoring: 2007-2014. Springer (2014).

\section{How to Cite This Article}

Hamzaban, M.T., Büyüksağiş, I.S., Manafi, M., and Touranchehzadeh, A., The effect of saturation on the physical and mechanical behavior of some rock samples, Civil Engineering Beyond Limits, 3(2021), 23-31. https://doi.org/10.36937/cebel.2021.003.005 